\title{
THE CASE OF THE FOAMING TOE
}

\author{
MAJ A D L GREEN, MB, FRCS \\ Cambridge Military Hospital, Aldershot
}

MAJ D N FAITHFULL-DAVIES, MB, MRCPath

David Bruce Laboratories, Everleigh

\section{SUMMARY: The difficulties of diagnosis and management of a yeast septicaemia following the infection of the big toe nail bed after avulsion of the nail.}

\section{Case Report}

A 23 year old soldier, a native of Sri Lanka, who was a former junior Commonwealth Games athlete, gave a history that during an athletics meeting in June 1980 a sixteen pound shot had been accidentally dropped onto his left toe which resulted in a sub ungual haematoma. Some weeks later a bloodstained discharge occurred from beneath the nail. He suffered no further trouble until January, 1981 when the left big toe became painful following a cross country run in wet shoes. Several days later there was a further discharge from beneath the nail, which was at first blood stained pus, but soon changed to a clear frothy discharge. He was referred for an out patient surgical opinion and was seen at the Cambridge Military Hospital on 1 May 1981. At that time there was no evidence of infection, but due to the severity of the ingrowing big toe nail avulsion was considered necessary, and he was placed on the waiting list for this procedure to be performed.

The nails were removed under local anaesthetic on 8 May 1981. The right nail bed healed rapidly, but suppuration of the left toe nail bed occurred within a few days of operation. From an early stage it was noted that the discharge was frothy, clear or pale yellow in colour and odourless. Bacteriological swabs taken from the discharge and from deep into the nail sulcus, grew Staphylococcus Aureus Eusol soaks were applied to the toe nail bed and treatment with penicillin was commenced on the basis of the swab report and also because clostridial infection could not be excluded. No improvement followed this course of therapy.

Subsequently Klebsiella aerogenes and a Streptococcus viridans were isolated, and despite appropriate antibiotic treatment no improvement was apparent. Culture for yeasts and fungi was carried out using Sabouraud dextrose agar; a scanty growth of Candida albicans occurred after five days incubation, at this time the growth of the organism was not considered significant. During this seven week period the infection remained localized around the big toe nail bed with no swelling of the toe. However during the following week the toe, foot and ankle became swollen, red and painful; the patient also complained of pain in the groin. For the first time he became pyrexial, the temperature remaining elevated at $38^{\circ} \mathrm{C}$. An X-ray of the phalanges of the big toe revealed no abnormality in the bony structure. No bacterial or fungal growth was demonstrated from multiple blood cultures.

Due to the worsening clinical situation and the failure to isolate a causative or- 
ganisms, an excision biopsy of the edges of the nail fold was performed. The small amount of material excised was referred for culture and histology. Primary culture of the biopsy material was carried out on blood agar (aerobically and anaerobical1y), chocolate agar and Sabourauds agar; a heavy growth of Streptococcus viridans (sensitive to penicillin $G$ ) and a scanty growth of Candida albicans was noted. No other organisms were isolated following subculture from an enrichment cooked meat medium. The histology revealed scanty fragments of keratinised tissue in which some yeast bodies and fungal hyphae could be discerned. The biopsy did not include organised subcutaneous tissue, thus no evidence of invasion of the vital tissue could be demonstrated.

A trial of an antifungal agent was considered to be justified at this time on the basis of the failure of the infection to respond to antibacterial agents, to the histological and microbiological evidence of the presence of fungi, and also because of evidence suggesting that the patient was physically interfering with the wound. Treatment with intravenous miconazole resulted in a prompt resolution of the patient's fever. After eight days treatment the swelling and pain in the foot had disappeared and the wound site was clean and healed. The patient was mobilised but the wound broke down eight days later. The patient was started on ketoconazole which resulted in rapid healing. The patient was discharged on 6 August after 93 days in hospital.

At the initial follow up four weeks later he was symptom free and had started athletic pursuits again, but he was readmitted on 4 September 1981 because the nail bed had again broken down due to interference with it by the patient.

\section{Discussion}

Avulsion of the toe nails is a surgical procedure which seldom leads to serious complications ${ }^{1}$; infection of the nail bed when it occurs usually responds rapidly to appropriate wound toilet and systemic antibiotics when required.

The clinical presentation of the case was unusual as the abundant clear odourless frothy discharge, maximal after wound toilet, suggested infection with a gas forming organism. The discharge contained scanty white cells but numerous bacteria. The possibility of a fungal infection was considered in the initial differential diagnosis, but had been rejected as being extremely unlikely in a patient who appeared to be immunocompetent; later investigations revealed no obvious deficiency in the patient's immune system.

Although there was lack of definite evidence for invasive fungal disease, it was considered that a therapeutic trial of miconazole was justified because of the patient's gradual clinical deterioration despite antibacterial therapy, and the increasing evidence that the patient was frequently interfering with the wound.

The rapid response to treatment suggested that the infection was probably due to a yeast, and was reinforced by the response to the relapse when treated with ketoconazole.

The difficulty in diagnosis of systemic fungal infection is well documented ${ }^{23}$; a further biopsy of the wound before treatment might have confirmed the diagnosis but this procedure was not considered appropriate at the time. 
It is possible that the infecting organism in this case was Candida albicans but another yeast of fungus, sensitive to miconazole, but more fastidious in its in-vitro growth requirements, may have been responsible.

\section{Acknowledgements}

The authors are grateful for the permission of Lt Col F B Mayes, FRCS, RAMC to use the clinical material from one of his patients, and to Sister King and staff for their patient nursing care.

\section{REFERENCES}

1. Murray W R. Onychocryptosis: Principles of non operative and operative care. Clin Orthop 1979; 142: 96-102.

2. EILARD T, Norrby R. Clinical diagnosis of systemic fungal infections. Scand $J$ Infect Dis 1978; (Suppl) 16: 15-22.

3. ACKerman N B, Kronmueller J. The importance of Candida as an infectious agent. Surg Gynec Obstet 1975; 140: 65-68.

\section{ACADEMIC ACHIEVEMENTS}

MRCP(UK)

MRCGP

MSc

(Occupational Medicine)

D Av Med
Maj B J Heap, MA, MB, BChir, RAMC. Maj N A Johnston, MB, BS, LMSSA, RAMC. Maj N J Riddell, MA, MB, BChir, RAMC.

Maj R N Haworth, MB, BS, MRCOG, DCH, RAMC. Capt J S Baillie, MB, BCh, DRCOG, BAO, RAMC. Capt I D Brown, MB, ChB, RAMC.

Lt Col J R Brown, MB, BCh, BAO, RAMC.

Maj S J Durnford, MB, BS, MRCS, LRCP, MRCGP, RAMC.

\section{Additional Qualifications}

The under-mentioned officers have been elected to the Fellowship of the Faculty of Community Medicine:-

Brig D S Paton, MBE. Cols P J Blackburn, A G Harwood, C J Lewthwaite. Lt Col I P Crawford, GM. 